\title{
MODOS
}

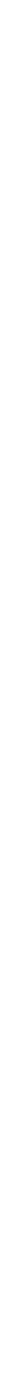

De Goa a Cabul: aventuras de um artista goês dos inícios do século XIX, José Maria Gonsalves (1800-1845)

From Goa to Lisbon: the adventures of a Goan artist from the early 19th century, José Maria Gonsalves (1800-1845)

\section{Dr. Helder Carita}

\section{Como citar:}

CARITA. H. De Goa a Cabul: aventuras de um artista goês dos inícios do século XIX, José Maria Gonsalves (1800-1845). MODOS. Revista de História da Arte. Campinas, v. 2, n.2, p.160-176, mai. 2018. Disponivel em: <http://www.publionline.iar.unicamp.br /index.php/mod/article/view/1157>;

DOI: https://doi.org/10.24978/mod.v2i2.1157

Imagem: Cerimónia hindu referida na legenda "Thirte lavagem dos gentios". José Maria Gonsalves. (atrib.), Goa c.1820. Coleção Particular. Estoril. 


\title{
De Goa a Cabul: aventuras de um artista goês dos inícios do século XIX. José Maria Gonsalves (1800-1845)
}

\author{
From Goa to Lisbon: the adventures of a Goan artist from the early 19th \\ century, José Maria Gonsalves (1800-1845)
}

\author{
Dr. Helder Carita*
}

\begin{abstract}
Resumo
Com uma obra enquadrada nas primeiras décadas do século XIX, e uma vida movimentada e aventurosa, circulando de Goa a Bombaim e até ao Afeganistão, José Maria Gonsalves emerge como uma figura emblemática, não apenas na história de Goa, como também na conjuntura cultural e sociopolítica da Índia Inglesa. $O$ seu interesse pelos diversos aspectos dos usos e costumes, a par de um gosto pela arquitectura, onde é notória uma clara tendência para a valorização dos pormenores e detalhes, tornam os seus desenhos e pinturas documentos incontornáveis para o conhecimento da arte indo-portuguesa como da história da presença portuguesa no Oriente sendo a sua obra presença indispensável nas grandes exposições internacionais que tem sido realizadas ao longo das últimas décadas. Igualmente as suas litografias, particularmente as de Bombaim, são uma referência académica fundamental para o estudo da arquitectura e desenvolvimento urbano desta cidade na primeira metade do século XIX1.
\end{abstract}

\section{Palavras chave}

Goa; arte indo-portuguesa; viajantes; Bombaim.

\begin{abstract}
Abstrat
With a work framed in the first decades of the nineteenth century, and a busy and adventurous life, circulating from Goa to Bombay and to Afghanistan, José Maria Gonsalves emerges as an emblematic figure, not only in the history of Goa, but also in the cultural and socio-political journey of English India. His interest in the various aspects of uses and customs, together with a taste for architecture, where a clear tendency towards the valorisation of details, makes his drawings and paintings documents indispensable for the IndoPortuguese art. Also his lithographs, particularly those of Bombay, are a fundamental academic reference for the study of the architecture and urban development of this city in the first half of century XIX.
\end{abstract}

\section{Keywords}

Goa; indo-Portuguese art; traveller; Bombaim. 


\section{Introdução}

Ao longo dos anos 90 do século passado, foi divulgado uma interessantíssima série de pinturas com figuras típicas de Goa cujas composições e temáticas transparecem uma forte curiosidade científica de marcado pendor lluminista. Embora não assinadas o interesse não só artístico como iconográfico destas obras levou a que fossem expostas em importantes exposições internacionais, cujo exemplo paradigmático foi a exposição realizada em Paris no ano de 1998, que celebrou os 500 anos da chegada dos portugueses à Índia, intitulada: Vasco da Gama e a Índia, e que teve lugar na Universidade da Sorbonne ${ }^{3}$.
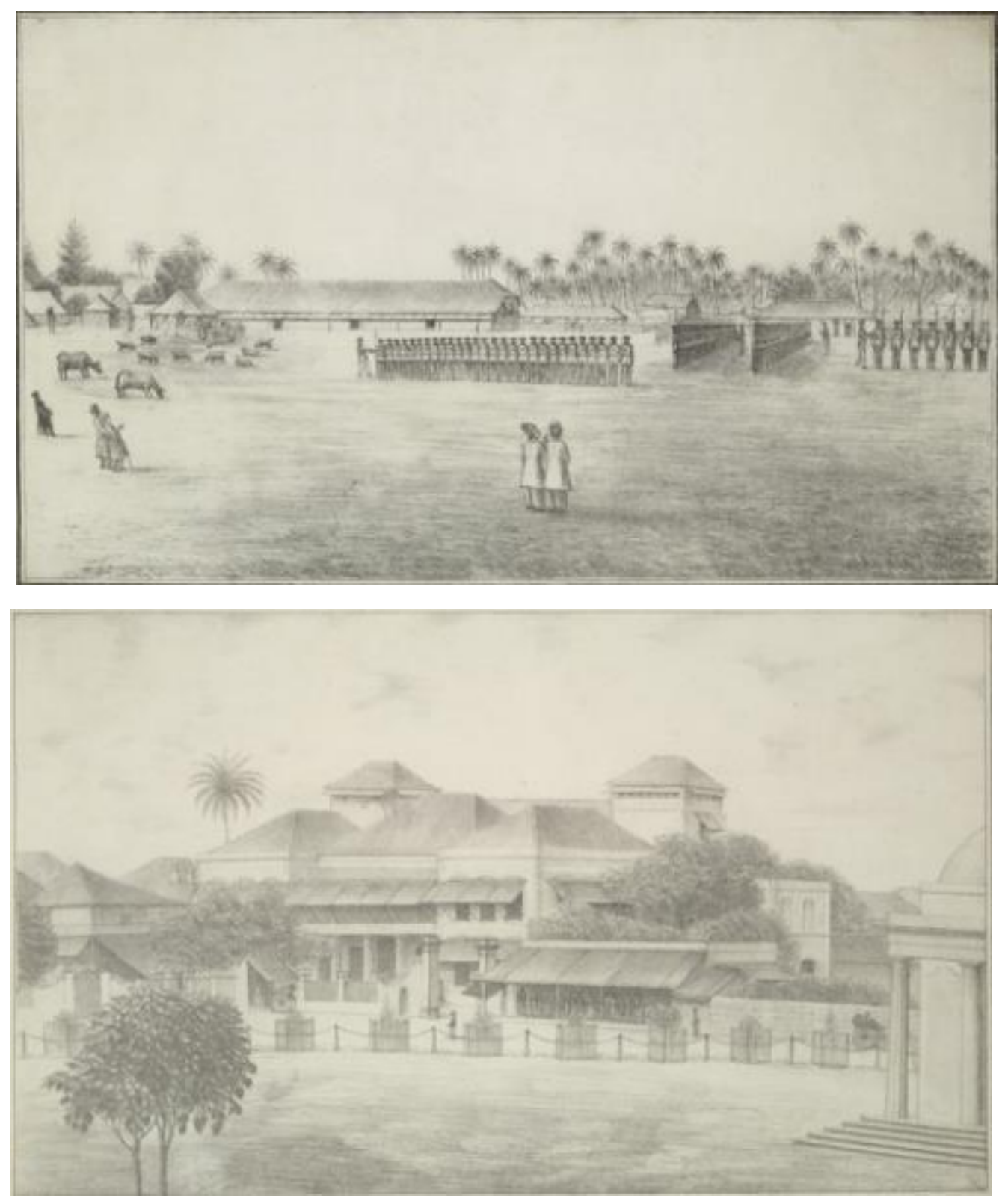

Figs. 1 e 2. Litografias com vistas de Bombaim. Assinado J. M. Gonsalves, 1826. 
$\mathrm{Na}$ sua temática estas pinturas exibem em primeiro plano personagens típicas de Goa enquadradas, em segundo plano, com alguns dos mais representativos conjuntos arquitectónicos situados na barra do Mandovi, hoje, na sua grande maioria desaparecidos. Estes fundos adquirem, em cada pintura, uma notória dicotomia que vemos ser evidenciada pelo próprio autor que coloca uma pequena legenda nas figuras do primeiro plano repetindo uma segunda legenda no fundo. Esta quase parceria confere ao segundo plano de cada pintura uma autonomia como documento patrimonial sobre arquitectura produzida em Goa, inscrevendo-se num discurso científico preocupado em produzir um saber sobre a história e as realidades dos lugares e que no Brasil tem a sua correspondência na Viagem Filosófica de Alexandre Rodrigues Ferreira. As pinturas de Goa, pelas suas características e detalhes são um pouco posteriores à Viagem Filosófica situando-se na primeira metade do século XIX. As diferentes legendas escritas em português, mas usando termos do vocabulário indo-português apontavam, desde 0 inicio da nossa investigação, para um artista goês o que confere a este conjunto um significado cultural muito particular, afastando-se de um discurso colonial de alguém que vem de fora para se afirmar como um discurso de um olhar de dentro, um "filho da terra".

Um alargamento do estudo das pinturas de Goa para a produção da Índia do século XIX levou à descoberta de um conjunto de litografias sobre Bombaim que apresentavam, a vários níveis, características muito idênticas com as referidas pinturas de Goa. Assinadas por J. M. Gonsalves, este conjunto de litografias divide-se em duas séries, uma de seis litografias a preto e branco, datada de 1826 [figs. 1 e 2], e uma outra a cores, também em número de seis, datada de 1833.

Digno de nota, as temáticas abordadas na primeira série de litografias de 1826 apresentam um ambiente ligado a instituições militares e da marinha, que se revela de forma mais clara em duas litografias muito semelhantes, com manobras e exercícios militares. Esta redundância, onde, em seis vistas de Bombaim, duas tratam do mesmo tema, permite equacionar a hipótese de 0 autor ter integrado o corpo de engenheiros portugueses radicado em Goa, emigrando para Bombaim depois de fazer a sua formação. A sensibilidade do autor à arquitectura, não só nos seus aspectos estéticos como construtivos, explicava-se assim. A emigração do pintor para Bombaim enquadrava-se num movimento das elites goesas católicas, que encontrava em Bombaim, na época, um quadro social e económico mais dinâmico e versátil, em contraponto com a letargia do meio económico e cultural de Goa.

De forma diferente, na segunda série de litografias, editadas em 1833, os temas abordados manifestam um carácter mais institucional, como se de um ambiente militar passássemos a um ciclo mais chegado à Administração. Nesta série predominam os edifícios governamentais como o Government House, em Parell, o Town Hall, a Apollo Gate, a New Mint e ainda a Igreja de Saint Thomas, que em 1816 fora elevada a catedral. Registrando, no seu conjunto, os edifícios mais notáveis da cidade de Bombaim, estas litografias representavam a afirmação da supremacia económica do Império Britânico no Oriente. Numa observação mais atenta às litografias, notamos que entre as duas séries de imagens verifica-se uma visível evolução do artista, que se manifesta num melhor domínio da perspectiva e do desenho de arquitectura na segunda série. Neste caso destacam-se, sobretudo, os desenhos dos edifícios do Town Hall [fig. 3], e do Palácio do Governador [fig. 4], em Parell, que apresentam não só um desenho mais fluente, mas também um melhor domínio de perspectiva, numa brilhante tradição do chamado desenho arquitectónico. 
Em paralelo com a sensibilidade à arquitectura, uma tendência permanente na obra de J. M. Gonsalves, que vemos emergir logo na primeira série de litografias a preto e branco, é sem dúvida a sua forte sensibilidade aos aspectos sociais e tradicionais que o levam a pontuar os seus enquadramentos arquitectónicos ou paisagísticos com personagens e cenas, que, humanizando os seus quadros, salientam aspectos socioculturais num discurso, que temos vindo a observar, que se integra numa tradição iluminista preocupada em promover um saber de pendor científico.
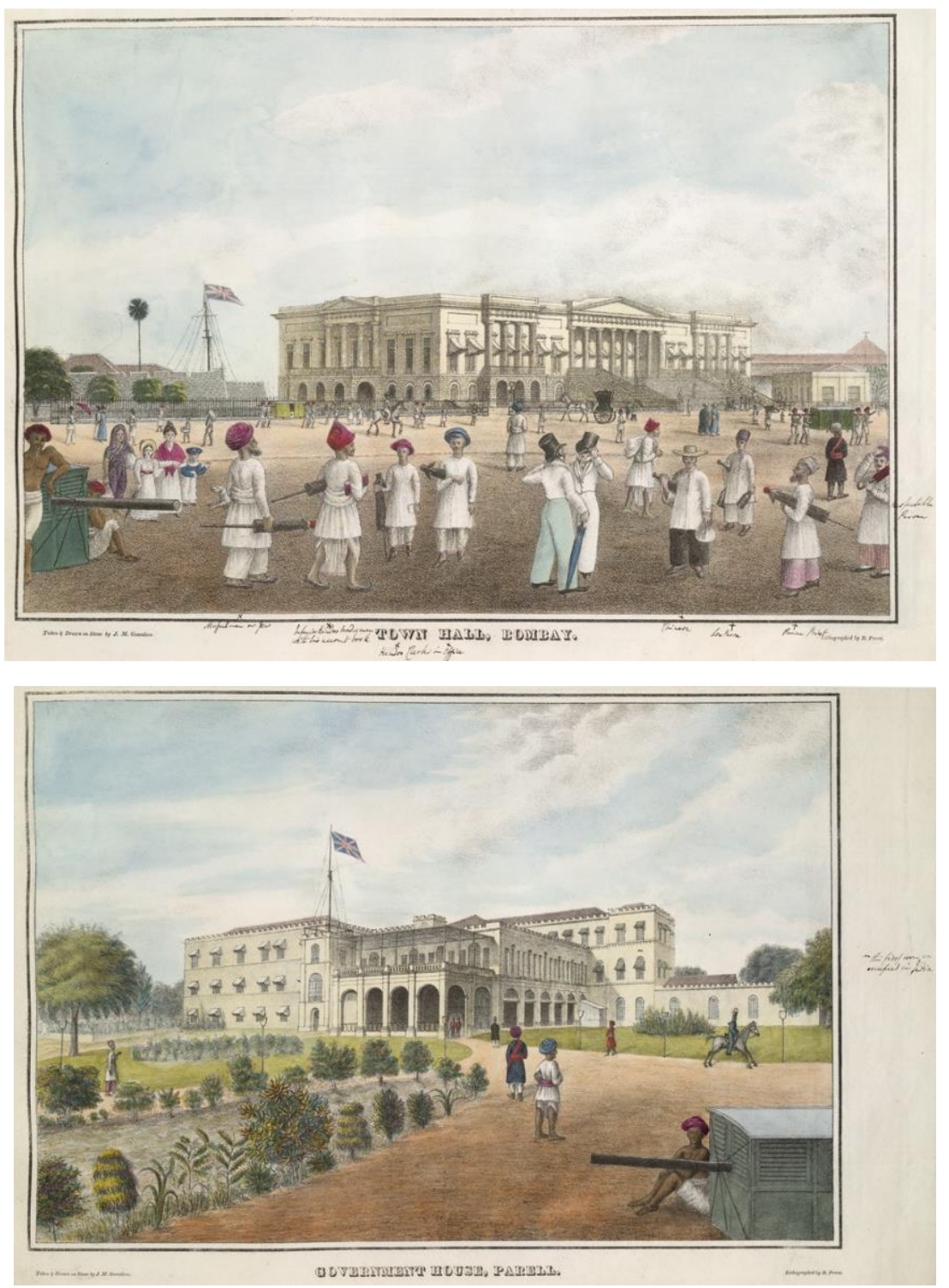

Figs. 3 e 4. Litografias de Bombaim com ao fundo a Câmara e o Palácio do Governador em Parell, arredores de Bombaim. Assinadas J.M. Gonçalves, 1833. 
Se durante alguns anos a referência a J. M. Gonsalves como artista goês permaneceu como uma hipótese sem um fundamento documental, o estudo de uma rara carta de Goa do século XIX veio-nos permitir relacionar documentalmente 0 artista J.M. Gonsalves como o desenhador e cartógrafo José Maria Gonsalves. Na realidade, nesta carta o artista aparece, não só, a assinar uma planta do território de Goa com o seu nome completo, como a assinar uma vista de Pangim com as suas iniciais, seguidas do seu nome de família, como observamos nas litografias de Bombaim.

Em grande formato $(134 \mathrm{~cm} \times 63 \mathrm{~cm})$ esta notável carta reúne várias plantas, desenhos, um com o túmulo de São Francisco de Xavier e outro com a fachada da Igreja de São Caetano e, ainda, duas magnificas vistas panorâmicas, uma de Pangim e outra de Velha Goa. A planta principal com o mapa do território de Goa é assinalada com uma grande cartela com, no interior, a legenda: "extrahido d'original dezenhado e litografado por José Maria Gonsalves Primeiro Desenhador n'Officio de Engenheiro Mor em Bombaim" (Mota, 1980: 62)4. [fig.5]
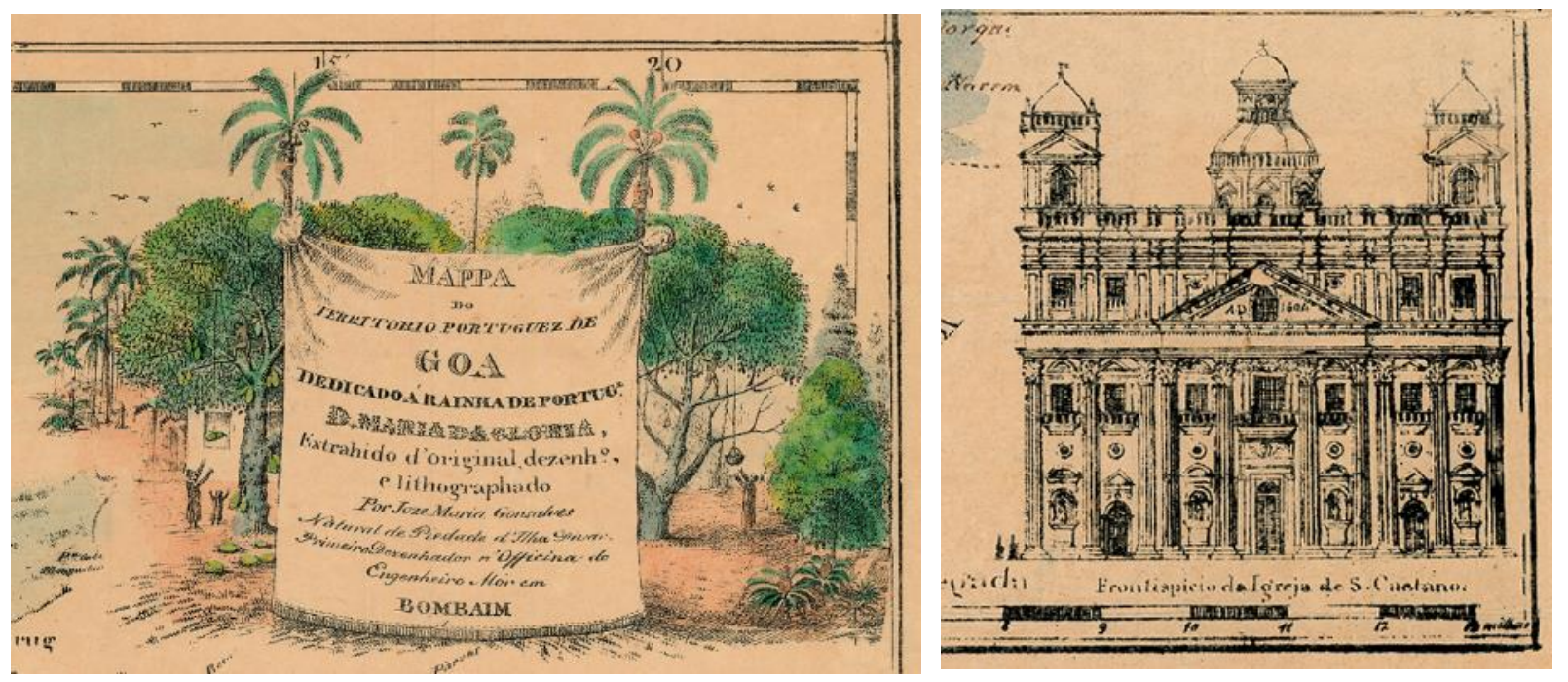

Figs. 5 e 6. Pormenor de Mappa de Goa com legenda e desenho com alçado da Igreja de São caetano em Velha Goa.

Esta legenda, identificando o artista como "desenhador junto do Engenheiro-mor" vem confirmar a ligação de José Maria Gonsalves à cartografia e engenharia militar que tínhamos assinalado no estudo das litografias de Bombaim. No mesmo sentido, a referida Carta de Goa inclui a um canto um alçado da Igreja de São Caetano manifestando um grande domínio na técnica do desenho arquitectónico que vemos serem uma constante da obra do autor [fig. 6]. Quanto à Vista de Velha Goa incluída na carta de Goa, ela é acompanhada com uma legenda de particular significado para o percurso da vida de José Maria Gonçalves ao referir: "Perspectiva da Cidade de Goa tirada d'Oiteiro da Piedade, em 1829, por J.M. G" [fig. 7]. Esta data em que 0 autor realiza a vista de Goa situa-se, assim, entre a primeira série de litografias datadas de 1826 e, antes da segunda série de 1833, comprovando que o artista se deslocou a Goa vindo de Bombaim. Além de Velha Goa, a carta integra ainda uma notável vista de 
Don Jose, for I must give him titles which, if not inherited, were readily accorded to him by everyone, was a Portuguese, a native of Goa, and educated at the Propaganda of that city. His forte was music, to which he added the sister accomplishment of drawing. Besides his own language he knew some Latin, a little French, and spoke tolerable English: in fact, he did high honour to the city of Albuquerque, and could sympathize with his illustrious countryman Camoens, when far from home (Idem: 71).

Pelas palavras de Alexander Burns podemos confirmar que José Maria Gonsalves nasceu em Goa no seio de uma família ligada às elites. Embora referindo-se ao artista como Dom José, Burns não deixa de fazer uma certa insinuação sobre a legitimidade do uso deste título assinalando, no entanto, que ele Ihe era reconhecido pelos seus pares. Esta condição relaciona-se com a sua apurada educação que do domínio de várias línguas se estendia às artes do desenho e da música, facto que Alexander Burns testemunha com clara estima e admiração ao escrever:

His heart he had left behind him, but not his good spirits, and his gay disposition and musical talents often enlivened us whilst on the Indus, and when the snows of Hindoo Koosh were frowning over us. The guitar was the Don's favourite instrument, but sometimes he played on the accordion, and would give us " Home, sweet Home" in our own native tongue, a "Ca ira" in French, a loyal air in Portuguese, or the merrier accompaniment to his own fandango (Ibidem: 31).

Pelas palavras de Alexander Burns ficamos, então, a saber que José Gonsalves terá sido não só o animador como um forte suporte psicológico face às agruras nas altas montanhas do Afeganistão. Um pouco em conclusão, Alexander Burns refere depois que o artista teria voltado para Bombaim para junto da sua "senhora", confirmando-nos que José Gonçalves estava instalado e casado em Bombaim, vivendo em Mazagão. Ainda, sobre a sua personalidade e carácter, Burns dedica-lhe um rasgado elogio ao afirmar:

(...) altogether Don Jose Gonsalves was a very original character, and a vast favourite with us all: during the day he laboured with industry and attention at his proper calling of draftsman; and when invited to join us after dinner, never failed to enliven the evening. He is I believe, still in Bombay, and, if this page meets his eye, I hope he will consider it as written with sincere good wishes for is future success, and accept my congratulations at his safe return to his senhora (Ibidem: 31 ).

De volta à Inglaterra, Alexander Burns redige a narrativa da sua Expedição, que será editada, em 1842, sob o título: Cabool: a Personal Narrative ${ }^{6}$. 0 texto é acompanhado por várias imagens dos trabalhos de José Maria Gonsalves, o que nos dá notícia dos desenhos realizados no decurso da Expedição. Nem sempre assinados, no conjunto destes desenhos destaca-se um alçado de um palácio, cujo tratamento e detalhe evidencia o seu gosto pela arquitectura, que vemos manifestar-se igualmente nas suas obras tanto de Bombaim como de Goa. Com a legenda "Front of the Raos Palace at Mandive" [fig. 9], a litografia tem a assinatura de J. M. Gonsalves. Talvez mais interessantes pela frescura e vivacidade do traço, são duas litografias representando guerreiros afegãos, igualmente assinadas, uma com a legenda "Deenbur a Siah-Posh kaffir" [fig. 10], e a segunda designada por "Peeroz a Jokeea Soldier". Marcados por uma notória fluidez e destreza, estes desenhos apresentam um cuidadoso tratamento 
tanto da fisionomia dos personagens como da sua postura e detalhes do vestuário, conferindo-lhes uma notável qualidade que não encontramos nas litografias que o autor realizara anos antes em Bombaim, o que nos atesta um percurso de amadurecimento estético e um desenvolvimento do domínio técnico.
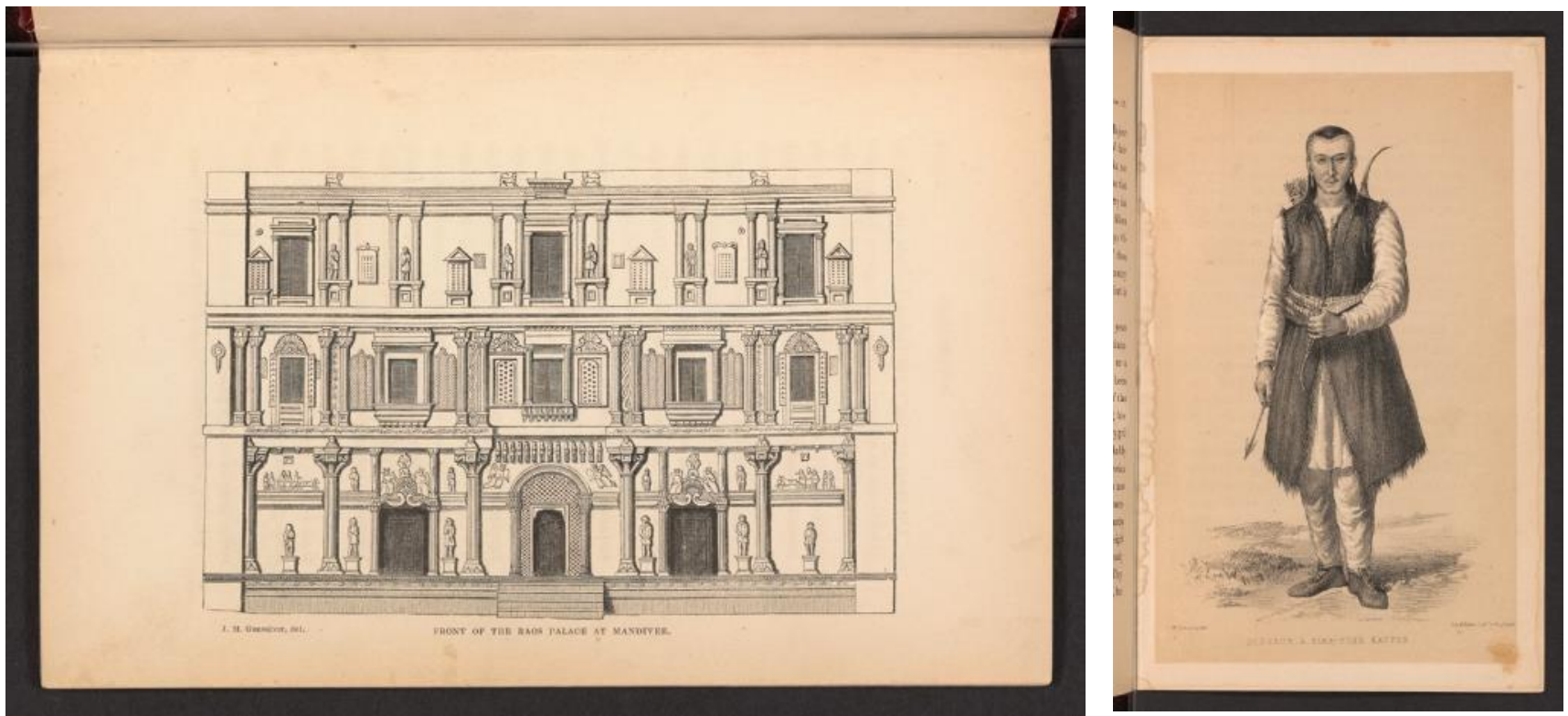

Figs. 9 e 10. Alçado do palácio Raos em Mandivee e soldado afgão Peeroz a Jokeea,assinados J. M. Gonsalves e inseridos no livro de Sir Alexander Burns, Cabool: a Personal Narrative, editado em Londres em 1842.

Em Bombaim, de onde José Gonsalves parte para a Expedição de 1836, terão sido fundamentais para a sua contratação as litografias que já tinha realizado sobre a cidade.

\section{Gentes e arquitectura de Goa}

No quadro geral da obra de José Gonsalves, o estudo das litografias, não só de Bombaim como as realizadas no Afeganistão, permite-nos atribuir a este artista o conjunto de telas a óleo aspectos sociais e arquitectónicos de Goa que, embora não assinadas apresentam, ao nível da composição e dos pormenores, inconfundiveis afinidades estilísticas com as litografias sobre Bombaim.

Tal como podemos observar nas litografias de Bombaim, em cada uma destas pinturas José Gonçalves associa um fundo edificado com uma ou mais figuras documentando usos e costumes de Goa. Neste conjunto de pinturas, 0 artista escolhe como pano de fundo as margens do estuário do Mandovi, onde, ao longo dos séculos, se foram implantando os mais importantes edifícios de Goa, colocando em primeiro plano os seus personagens, que aparecem assim associados a cenários de notório impacto visual. Como afirmamos anteriormente, de forma muito original, tanto os fundos arquitectónicos, como os personagens destacados no primeiro plano, surgem com uma pequena legenda escrita num português pontuado de traços luso-goeses. É o caso da pintura com Daugim ao fundo, onde em primeiro 
plano aparece um casal, sendo a mulher referida por "Bahe" [fig. 11], termo de origem concani que significa menina, embora podendo estender-se a jovens mulheres casadas (Dalgado, 1988: 79-80). Igualmente de origem concani é a legenda do homem nomeado como "Begarim" que significa trabalhador. Outro exemplo de legenda, desta vez de origem marata, mas usado em Goa, é o termo angraca, "...espécie de blusa que índios e maumetanos usam fora de casa..." (Idem: 45), que vemos ser referido como traje de um "gentio" numa pintura com Pangim em fundo [fig. 12].

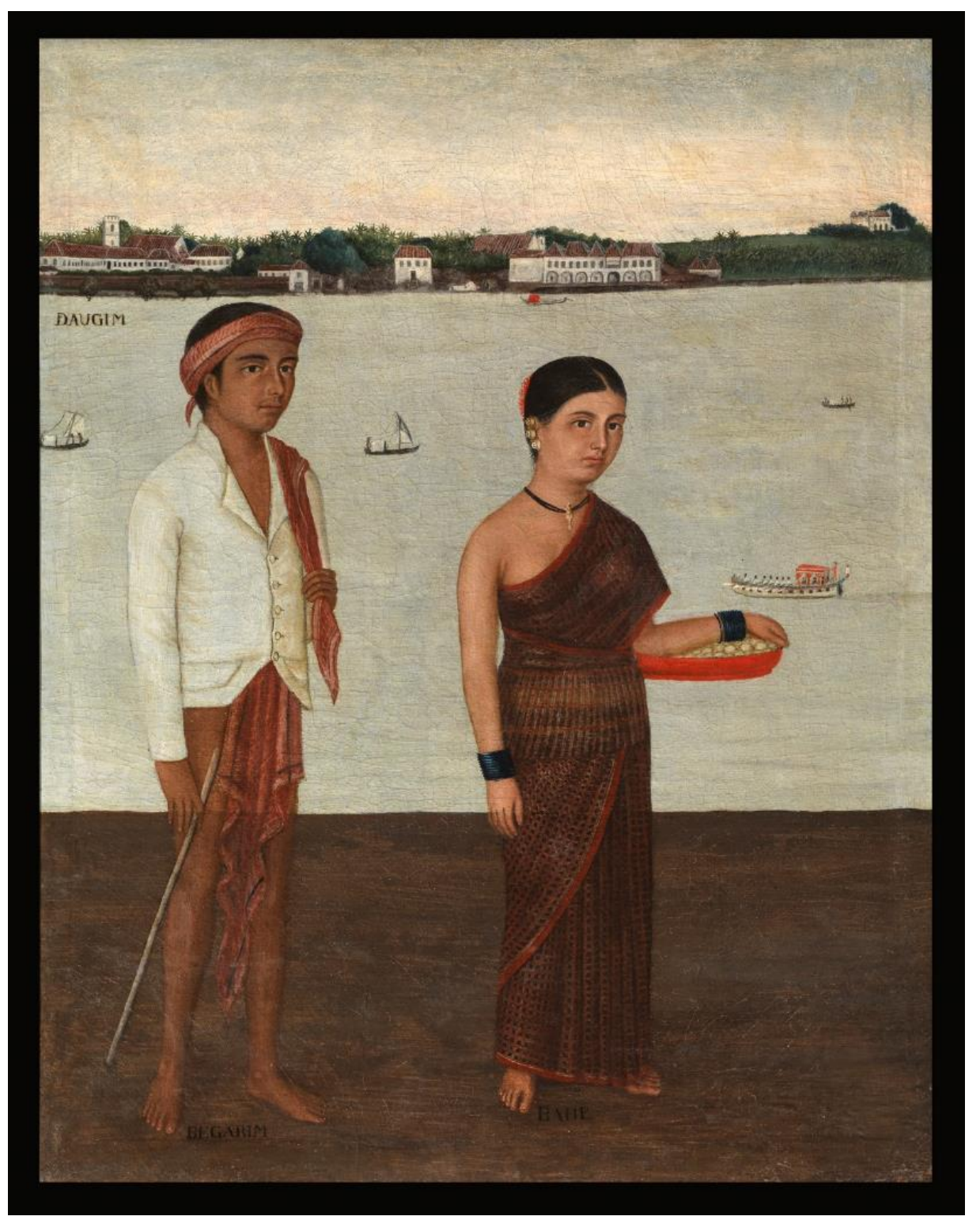

Fig. 11. Casal de camponeses hindu, vendo-se Daugin em segundo plano. José Maria Gonsalves. (atrib.), Goa c.1820. Coleção Particular. Londres e Estoril. 


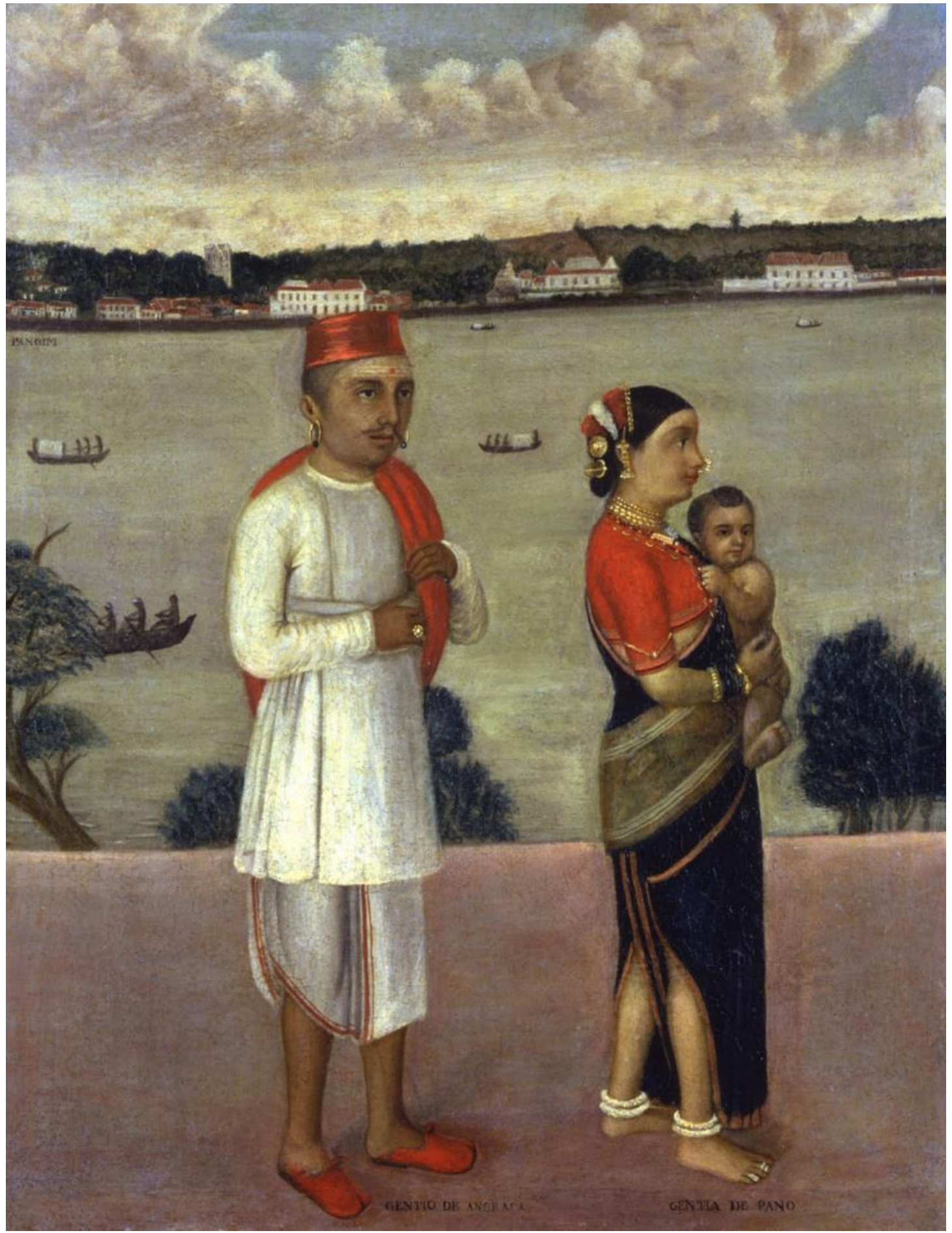

Fig. 12. Casal hindu, com uma criança ao colo da mãe, vestindo o homem "angarca" e a mulher "capod" com Pangim em segundo plano. José Maria Gonsalves. (atrib.), Goa c.1820. Coleção Particular. Londres e Estoril. 

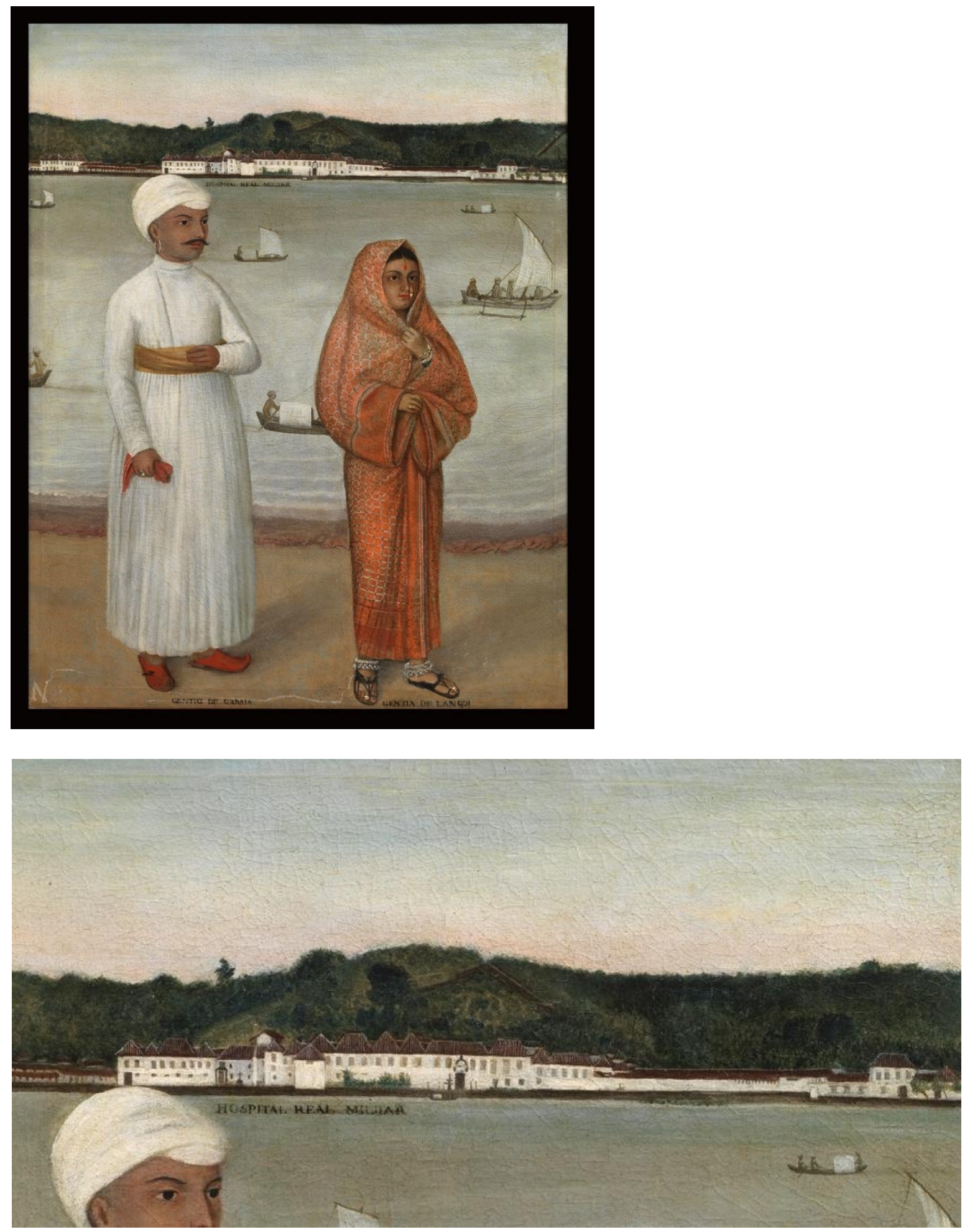

Fig.13 e 13a. Casal hindu vestido com cabaia e lençol, tendo ao fundo uma vista do Hospital Real Militar, antigo Palácio da Casa da Pólvora. José Maria Gonsalves. (atrib.), Goa c.1820. Coleção Particular. Londres. 
Numa visão de conjunto, desta série de pinturas com paisagens situadas nas margens do Mandovi, chegaram até nós seis vistas da margem sul e três vistas da margem norte deste rio. Da margem sul, na zona mais retirada do interior, a série de pinturas começa pela antiga aldeia de Dangim, onde vemos recortar-se ao fundo o convento da Madre de Deus e o Palácio de Recreio dos Vice-reis. Avançando no sentido da barra, segue-se a segunda pintura, com a aldeia de S. Pedro de Panelim com um conjunto de grandes palácios com fachadas orientadas ao Mandovi, à direita a fachada da capela de N. Sra da Piedade, e em cima o Palácio de Recreio dos Arcebispos. Como terceira vista, segue-se a pintura com o Hospital Real Militar, antigo Palácio e Casa da Pólvora [fig. 13]. Na quarta pintura surge a aldeia de Ribandar, seguindo-se duas vista de Pangim. Numa primeira vista da cidade destaca-se o Palácio do Governo, à direita, e, no lado oposto, o Palácio dos Noronha. Na segunda vista de Pangim, representando a sua zona ocidental, destaca-se o casario da cidade de que emergem, à esquerda as torres da igreja da $\mathrm{N}^{\mathrm{a}} \mathrm{Sr}^{\mathrm{a}}$ da Conceição, e, à direita, os palácios dos Soares, dos Almeidas e dos Ataide Teive, vulgarmente chamado dos Maquinés.

A segunda série de pinturas, com vistas da margem norte, inicia-se, numa lógica geográfica, com o forte de Aguada situado na embocadura do Mandovi, olhando o oceano Indico. Nesta sequência a segunda pintura representa os Reis Magos, com o forte em cima e a Igreja e Convento franciscano do mesmo nome. Como terceira e última vista temos a aldeia de Verem como pano de fundo.

$\mathrm{Na}$ lógica iconográfica deste conjunto, é notória a falta das telas, que seriam as mais emblemáticas, referentes a Velha Goa, onde julgamos que, em primeiro plano, estaria representada a elite portuguesa de origem europeia. Este grupo social, que ocupava os altos cargos de Administração, era designado em Goa como os descendentes. Entendido como uma espécie de casta, este grupo social vai perdendo importância ao longo do século XIX e XX, regressando à generalidade das famílias mais importantes à Europa. Como vemos nas litografias de Bombaim, as figuras colocadas em primeiro plano tendem a ilustrar aspectos tipológicos relacionados com o carácter dos edifícios que se recortam no fundo. Assim, em frente de um edifício de caracter militar, como é o forte de Águada, o artista coloca três tipos de militares, assinalando na legenda: CIPAI, CABU e um MOIRO. No mesmo sentido, como primeiro plano da vista da aldeia de São Pedro de Panelim, onde se encontravam alguns dos mais emblemáticos palácios da periferia da cidade de Goa, 0 autor coloca a figura de uma senhora brâmane, que 0 artista designa como BRAMINA, evidenciando o seu estatuto com traje de cerimónia e jóias adequadas á sua alta posição social [fig.14].

Como vemos nas litografias de Bombaim, as figuras colocadas em primeiro plano tendem a ilustrar aspectos tipológicos relacionados com o carácter dos edifícios que se recortam no fundo. Assim, em frente de um edifício de carácter militar, como é o forte de Águada, o artista coloca três tipos de militares, assinalando na legenda: CIPAI, CABU e um MOIRO. No mesmo sentido, como primeiro plano da vista da aldeia de São Pedro de Panelim, onde se encontravam alguns dos mais emblemáticos palácios da periferia da cidade de Goa, 0 autor coloca a figura de uma senhora brâmane, que 0 artista designa como BRAMINA, evidenciando o seu estatuto com traje de cerimónia e jóias adequadas á sua alta posição social [fig. 14]. 


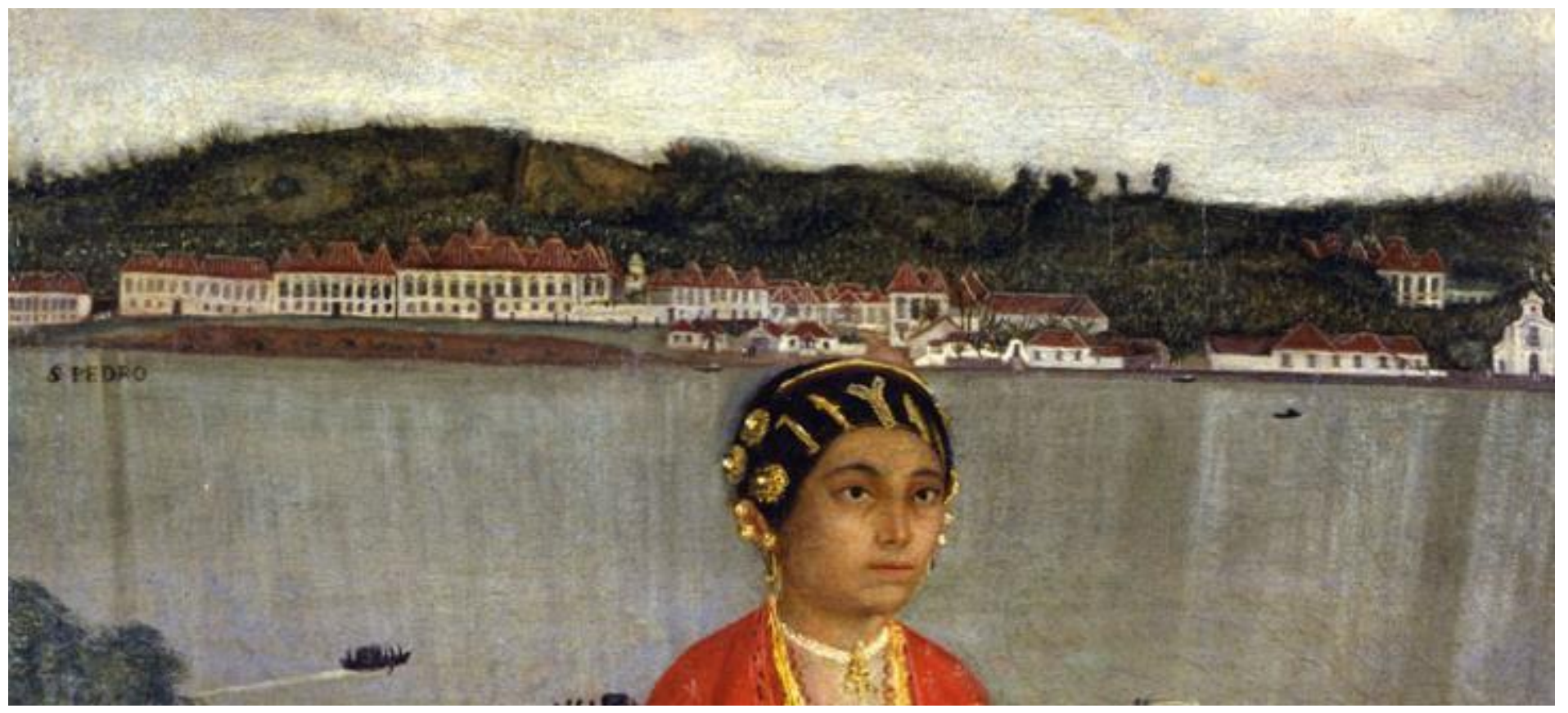

Fig.14. Brâmane, tendo ao fundo a aldeia de São Pedro onde se destacam vários palácios da nobreza portuguesa. José Maria Gonsalves. (atrib.), Goa c.1820. Coleção Particular. Estoril.

De interpretação mais complexa mas muito estimulante, é a figura de jovem vestido à europeia, com o Palácio do Governo como fundo, designado na legenda por CANARIM. Este termo, que nos séculos XVI e XVII queria dizer natural de Goa, passou, no século XIX, a associar natural de Goa com católico, facto cujo traje à europeia da figura, com casaca, colete e calção, sugere tratar-se da representação de um brâmane católico. Com guarda-sol e uma sacola, normalmente utilizada para transportar livros e documentos, a figura adquire estatuto de funcionário da Administração, correspondendo talvez, de forma mais ou menos inconsciente, ao retracto do próprio artista e do seu estatuto social.

Fora desta série com vistas sobre as margens do Mandovi, situa-se uma pintura com um fundo representando uma zona do interior de Goa. Mantendo claras afinidades com toda a obra de José Maria Gonçalves, 0 autor usa o seu esquema compositivo habitual de colocar duas legendas, uma sobre 0 fundo, aí designado como "MALNA", e uma segunda, sobre o primeiro plano registando uma cena de refeição tradicional, assinalada na legenda por "JANTAR DOS GENTIOS". Mais uma vez o autor elege a arquitectura como elemento preferencial colocando, no fundo da sua pintura, uma quinta de recreio que se destaca pelos seus tectos de tesoura e estrutura de pátios murados. 

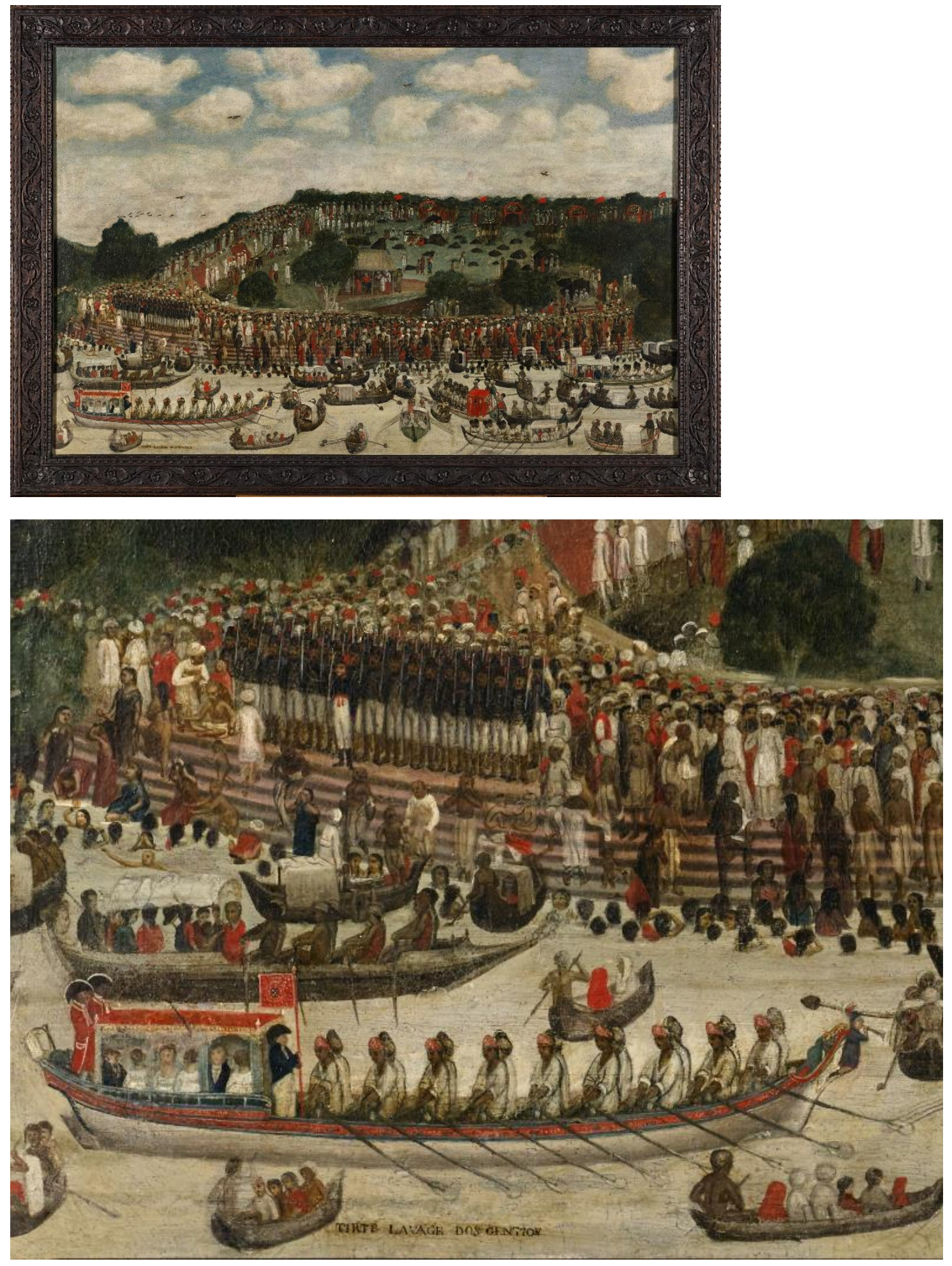

Figs. 15 e 15a. Cerimónia hindu referida na legenda "Tirte lavagem dos gentios". José Maria Gonsalves. (atrib.), Goa c. 1820. Coleção Particular. Estoril. 
Outro caso isolado é uma curiosa pintura, com a representação de uma cerimónia solene de abluções. Numa composição ao baixo, a cerimónia desenrola-se nas margens do Mandovi, ao longo de uma larga escadaria que ocupa toda a largura do quadro. Em primeiro plano, as margens do rio apresentam-se repletas de embarcações, onde se destacam vários escaleres armados de pavilhão. Pela legenda, que refere "TIRTE LAVAGEM DOS GENTIOS" [fig. 15].

Com origem no sânscrito, a palavra Tirta tem um significado muito amplo de lugar sagrado, ritual, águas sagradas (Dictionnaire Sanskrit-Français, 1987: 225). Em Goa a palavra refere, também uma célebre festa que se realizava em Agosto e que Lopes Mendes, na sua India Portuguesa, descreve: "ao sudoeste do pagode de Peligão, na margem direita do Mandovy, fronteira à ilha de Jua, tem lugar no mês de Agosto a feira e a festividade anual gentílica chamada Thirta" (Lopes Mendes, 1886: 272-273). Digno de relevo é, sem dúvida, a presença numa cerimónia religiosa hindu de um conjunto de autoridades oficiais portuguesas em escaleres engalanados, aí se evidenciando o bergantim do Vicerei, que se destaca pela equipagem de remadores e pelo lacaio segurando o estandarte com as armas reais.

Sobre o período ou data da realização das vistas de Goa, os dados levantados sobre a obra e vida de José Maria Gonsalves permitem-nos confirmar que o conjunto destas pinturas terá sido realizado no início da sua carreira, eventualmente antes da sua partida para Bombaim. Nas representações arquitectónicas que vemos figurar nos segundos planos destas pinturas verificamos uma certa ingenuidade que sentimos, igualmente, na primeira série de litografias a preto e branco, datadas de 1826, e que vemos diluir-se, por sua vez, na série a cores das litografias de Bombaim datadas de 1833. Esta análise que coloca as pinturas de Goa no início da carreira do autor, ganha uma outra consistência quando comparamos a representação de Pangim nas pinturas de Goa e a Vista de Pangim incluída na Carta de Goa assinada pelo artista. Na realidade, enquanto na vista de Pangim incluída na Carta de Goa a nova Alfandega emerge no casario com uma clara preponderância, na pintura de Goa com Pangim ao fundo, o edifício da alfândega encontra-se omisso, permitindo concluir que as pinturas foram realizadas numa época claramente anterior à construção do edifício que foi construído durante 00 governo de D. Manuel de Portugal e Castro (Azevedo, 1842: 172), mais concretamente entre 1827 e 1835.

Se na Exposição da Sorbone, em 1998, o autor da série de pinturas com Gentes de Goa ainda era dado como anónimo, um percurso foi entretanto percorrido no sentido de um melhor conhecimento da personalidade do artista goês José Maria Gonsalves, como da extensão e diversidade da sua produção artistica. Pelo retracto efectuado por Alexander Burns, que agora se lhe associa, ficamos a saber muito da sua cativante personalidade de artista, músico e aventureiro. Ao seu perfil psicológico podemos acrescentar o conhecimento da sua obra produzida em Bombaim, e, muito particularmente, dos seus desenhos realizados no âmbito da sua expedição ao Afeganistão. 


\section{Referências}

AZEVEDO, Manoel Felicisimo Louzada d'Araujo d'. Segunda memória descriptiva e estatistica das possessões portuguezas na Asia e seu estado actual. Annaes Marítimos e Coloniais, $2^{a}$ série, n. 3, 1842.

BURNS, Sir Alexander. Cabool: a personal narrative of a journey to, and residence in the city in the years 1836, 7, and 8. London: John Murray, 1842.

DALGADO, Sebastião Rodolfo. Glossário luso asiático. vol. I. New Delhi: Asian Educational Services, 1988.

DICTIONNAIRE SANKRIT-FRANÇAIS.

Stchoupak, Nitti, Renou, Paris: Librairie D’Amérique et D'Orient, 1987.
DWIVEDI, Sharada; MEHOROTA, Rahul. Bombay the cithis within. Bombaim: India Book House PVT, 1995.

ROHATGI, Pauline; GODREJ, Pheroza J. Scenic splendours: India through the printed image. London, New Delhi: The British Library London and Arnold Publishers New Delhi, 1989.

GRACIAS, José António. Mappa de Goa por José Maria Gonçalves e varias cousas. Subsidios para a história da cartografia goesa. O Oriente Português, $1^{\text {a }}$ série, vol II, 1905.

LOPES MENDES. A India portuguesa. vol. I. Lisboa: Imprensa Nacional, 1886.MOTA, António Teixeira da. Cartas antigas da India existentes em Portugal (séculos XVIII, XIX, XX). Coimbra: Universidade de Coimbra, 1980.

\section{Notas}

\footnotetext{
* Doutor em História da Arte-Arquitectura e Urbanismo pela Universidade do Algarve. Pesquisador da FCT, vinculado à Universidade Nova de Lisboa, publicou diversos livros sobre patrimônio arquitetónico e urbanístico de Goa e Portugal. Email: hc.atelier@clix.pt. ${ }^{2}$ Como exemplo de uma obra académica onde as litografias de José Gonçalves ocupam um lugar de destaque, podemos referir a obra de Dwidevi; Mehorota, 1995.

3 Trabalho realizado no âmbito do projecto pós-doutoramento "Arquitectura regimentada em Portugal, séculos XVI a XVIII: processos de regulamentação desenvolvidos pela Provedoria de Obras Reais no seu tempo longo" (FCT/DFRH/SFRH/ BDP/86848/2012), com financiamento da Fundação para a Ciência e a Tecnologia, comparticipado pelo Fundo Social Europeu e por fundos nacionais do Ministério da Educação e da Ciência.

${ }^{4}$ As pinturas foram igualmente incluídas na Exposição Encontro de Culturas, Oito Séculos de Missionação Portuguesa, ocorrida em 1994, em Lisboa.

${ }^{5}$ A planta encontra-se no Instituto Geográfico Português, CA-589.

${ }^{6}$ Apresento aqui os meus agradecimentos à Dr ${ }^{0}$ Pheroza J. Godrej, que amavelmente me forneceu esta informação, referida no seu livro (Rohatgi; Godrej, 1989).

7 Na sequência de uma revolta Alexander Burns e seu irmão são assassinados em Kabul em 1841 sendo o seu livro editado postumamente, em 1842.
}

Artigo recebido em janeiro de 2018. Aprovado em abril de 2018. 